


\section{Queijos artesanais: fonte de bactérias ácido láticas selvagens para formulação de fermentos tradicionais}

\section{Artisan cheese: a potential source of wild lactic acid bacteria to obtain new starter cultures}

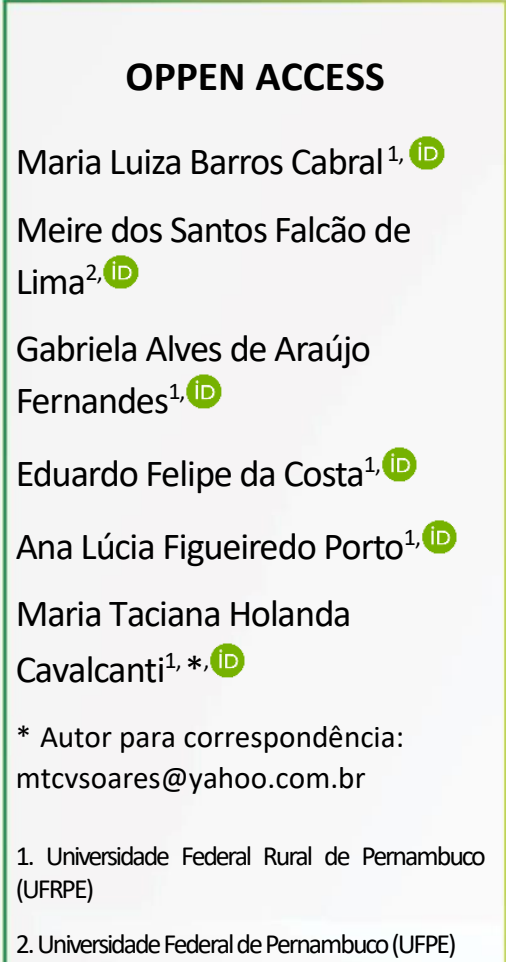

\section{Informações adicionais}

Recebido em: 29/06/2016

Aceito em: 07/11/2016

Publicado em: 20/12/2016

Editor:

Victor Hugo Gomes Sales

Instituto Federal do Amapá, Macapá, AP. jbfs@ifap.edu.br

\section{Avaliação às cegas por pares}

Processos de revisão

Prot. 1112016R01 (Brasil)

Prot. 1112016R02 (Brasil)

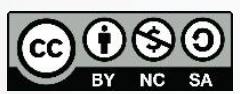

JBFS all rights

Copyright: (C) 2016

\begin{abstract}
ID JBFS1112016
DOI 10.18067/jbfs.v3i4.111

O objetivo desse trabalho foi avaliar os aspectos tecnológicos de bactérias ácido láticas isoladas a partir de queijo de coalho artesanal para o desenvolvimento de um fermento. Sendo assim, foi realizado isolamento, identificação clássica, capacidade acidificante ( $\mathrm{pH}$ e produção de ácido lático), proteolítica e antagonista de bactérias ácido-láticas. Os resultados obtidos mostraram que a população bacteriana encontrada foi composta em sua maioria por cocos, com presença dos gêneros Lactococcus, Leuconostoc, Enterococcus, e Streptococcus, além dos Lactobacillus, numa proporção aproximada de 1:3,5:13:2:1,5. Foram observadas bactérias classificadas como rápidas e lentas acidificantes, sendo esse equilíbrio importante para a formulação de um novo fermento. Em relação à capacidade proteolítica, no teste qualitativo de produção de proteases, poucas apresentaram halos, entretanto, todas produziram enzimas proteolíticas extracelulares, com pico de produção entre 24 e $48 \mathrm{~h}$ de cultivo, chegando até $11,71 \mathrm{U} / \mathrm{mL}$ de atividade total. Um total de $42,2 \%$ das bactérias avaliadas apresentou atividade antagonista frente a Escherichia coli, Klebsiella pneumoniae e Staphylococcus aureus. Pode-se, então, concluir que as bactérias ácido láticas isoladas a partir dos queijos de coalho artesanais possuem características importantes para a indústria de produtos lácteos na utilização como culturas starters.
\end{abstract}

Palavras-chave: Capacidade acidificante. Protease extracelular. Atividade antimicrobiana.

\section{ABSTRACT}

Our study aimed to evaluate technological aspects of lactic acid bacteria isolated from artisan coalho cheese, for obtaining a new starter culture. For this purpose, different bacterial genera were isolated, identified and determined as their acidifying capacity ( $\mathrm{pH}$ and lactic acid), antagonist activity and proteolytic activity. The results showed that the bacterial population consisted mostly of cocci, among which are Lactococcus, Leuconostoc, Enterococcus and Streptococcus, in addition to Lactobacillus in an approximate ratio of 1:3.5:13:2:1.5, respectively. The microorganisms were classified as fast and slow acidifying, an important balance to the formulation of a new starter culture. Regarding the proteolytic capacity, the qualitative test for protease production showed only few halos, although all extracellular extracts have presented proteolytic enzymes with peaks of production (maximum of 11.71 $\mathrm{U} / \mathrm{mL}$ ) between 24 and 48 hours of cultivation. Around $42.2 \%$ of the analyzed bacteria showed antagonistic activity against Escherichia coli, Klebsiella pneumoniae and Staphylococcus aureus. Therefore, it is possible to assume that the lactic acid bacteria isolated from artisan Coalho cheese have great potential for the use in dairy industry as starter cultures.

Keywords: Acidifying capacity. Extracellular protease. Antimicrobial activity. 


\section{INTRODUÇÃO}

O queijo de Coalho é produzido a partir de leite cru ou pasteurizado e possui um elevado valor comercial, devido à simples tecnologia aplicada, durante a sua fabricação, ao alto rendimento e à boa aceitação por parte dos consumidores. ${ }^{1}$ Este alimento é fabricado principalmente no Nordeste do Brasil: Pernambuco, Ceará, Rio Grande do Norte e Paraíba, tendo importância considerável na economia, apresentando impacto direto na renda dos produtores de leite, especialmente, aqueles que não têm acesso a plantas industriais de processamento de leite. ${ }^{2}$

A diversidade das bactérias ácido láticas (BAL) é considerada o fator principal do diferencial sensorial desses produtos artesanais. ${ }^{3} \mathrm{O}$ aroma dos queijos obtidos pela fermentação do leite cru é diretamente associado à raça, ao tipo de nutrição das fêmeas, ao processo de fabricação tradicional e à microbiota autóctone, que é responsável pela fermentação e maturação próprias da região produtora, ${ }^{4}$ fornecendo, assim, características diversificadas em locais diferentes. ${ }^{5}$

As BAL são empregadas na tecnologia de alimentos por causa de sua contribuição no aroma, textura, valor nutricional e segurança microbiológica em alimentos fermentados, além de serem produtoras de enzimas proteolíticas, exopolissacarídeos ${ }^{3}$ e substâncias antimicrobianas, como as bacteriocinas e antibióticos. ${ }^{6}$

Devido às suas propriedades metabólicas, as BAL apresentam significativo efeito inibitório sobre o crescimento e a produção de toxinas de muitas outras espécies de bactérias. Esta atividade antagônica pode ser devido à competição por nutrientes, diminuição do potencial redutor, redução do pH, devido à produção de ácido láctico, produção de compostos inibidores, como peróxido de hidrogênio, dióxido de carbono e diacetil .?

A produção de derivados lácteos no Brasil utiliza culturas iniciadoras, comercializadas por empresas estrangeiras, no entanto, o mercado brasileiro tem potencial para isolamento de bactérias ácido láticas de produtos artesanais, como o queijo de Coalho. $\mathrm{O}$ uso destas culturas fermentadoras de leite seria bastante útil na condução da formulação de novos produtos com características similares ao produto de origem destas estirpes. ${ }^{6}$ Assim, as BAL isoladas do queijo de coalho podem fortalecer o desenvolvimento de fermentos para a fabricação de derivados lácteos funcionais, pois já há comprovações de antagonismo in vitro frente a patógenos alimentares desses microrganismos. ${ }^{8}$

Inovações em alimentos lácteos têm apresentado avanços no mercado, numa taxa mais alta que a de outros produtos. $^{9,10} \mathrm{O}$ isolamento e o conhecimento das potencialidades tecnológicas de linhagens de BAL de nichos não investigados podem ser vantajosos por revelar características de linhagens com particularidades funcionais interessantes. ${ }^{11}$ Sendo assim, este trabalho teve como objetivo avaliar aspectos tecnológicos de bactérias ácido láticas selvagens para a formulação de um fermento, utilizando cepas isoladas de queijos de Coalho artesanais produzidosem três municípios da região Agreste do Estado de Pernambuco.

\section{MATERIAL E MÉTODOS}

\section{A) Isolamento das bactérias ácido láticas do queijo de Coalho}

Bactérias isoladas na temperatura de $30^{\circ} \mathrm{C}$ e $37^{\circ} \mathrm{C}$ a partir de três Queijos de Coalho artesanais produzidos nos municípios localizados dentro da Região Agreste do Estado de Pernambuco foram utilizadas neste estudo. Estes microrganismos foram caracterizados, previamente, como bactérias ácido láticas por coloração de Gram e teste de catalase. Aproximadamente 200 amostras fazem parte da coleção de bactérias ácido láticas pertencentes ao Laboratório de Tecnologia de Bioativos da Universidade Federal Rural de Pernambuco (Labtecbio-UFRPE), dessas 42 (três com morfologia de bastão e 39 com morfologia de cocos) foram aleatoriamente escolhidas, sendo 12 do queijo do município de Venturosa, 14 do queijo do município de Arcoverde e 10 do queijo do município de Capoeiras e reativadas com passagens sucessivas em Leite Desnatado Reconstituído (LDR) a 12\% para a diferenciação nos principais gêneros reconhecidos e para a realização de todos os experimentos propostos neste trabalho.

\section{B) Identificação das bactérias ácido láticas isoladas do queijo de Coalho}

A diferenciação de gênero para as BAL com morfologia de cocos (Lactococcus, Leuconostoc, Streptococcus, Enterococcus) foi efetuada com base nos testes de crescimento dos isolados em caldo APT (Himedia, Índia) nas seguintes condições: temperatura de 10 e 45으, pH de 4,4, e 9,6 , teor de $\mathrm{NaCl} 6,5 \%$ e produção de $\mathrm{CO}_{2}$ a partir da glicose. As BAL em formato de bastão (Lactobacillus) foram submetidas aos mesmos testes citados acima, no entanto foram incubadas respectivamente por dois e a cinco dias. Para a confirmação do gênero Streptococcus, foi realizado um teste adicional com crescimento a $60^{\circ} \mathrm{C}$.

\section{C) Capacidade acidificante das bactérias ácido láticas isoladas do queijo de Coalho}

Para avaliação da capacidade acidificante e alteração de $\mathrm{pH}$, foi utilizada a metodologia descrita por Franciosi et al. ${ }^{3}$ modificada $\bar{a}_{\overline{\mathbf{z}}}$ pela alteração nos tempos de avaliação do $\mathrm{pH} \mathrm{e}$ teor de ácido lático (0, 3 e 24h). As bactérias foram reativadas 
como descrito acima, a seguir, foram crescidas por 18 horas em caldo APT, centrifugadas a $10.192 \times$ por 10 minutos, lavadas com água peptonada estéril e inoculadas $1 \%(\mathrm{v} / \mathrm{v}) \mathrm{em} 9 \mathrm{~mL}$ de leite integral $\mathrm{UHT}$, incubadas na mesma temperatura de isolamento de $30^{\circ} \mathrm{C}$ ou $37{ }^{\circ} \mathrm{C}$. A taxa de acidificação foi medida em pHmêtro (HANNA HI 2221, Roménia) e calculada de acordo com Ayad et al. ${ }^{12}$. As cepas foram classificadas em rápidas, médias ou lentas, dependendo do tempo em que ocorreu a diferença de $\mathrm{pH}$ em $0,4 \mathrm{U}$ em relação ao valor inicial. A temperatura de incubação foi a mesma utilizada na reativação (30ํ ou $\left.37^{\circ} \mathrm{C}\right)$. Todas as análises foram realizadas em duplicata.

\section{D) Atividade proteolítica das bactérias ácido láticas isoladas do queijo de Coalho}

Para a determinação da atividade proteolítica extracelular qualitativa, as bactérias foram semeadas em meio sólido composto por $1 \%(\mathrm{v} / \mathrm{v})$ de leite desnatado e $1,5 \%$ de ágar, como descrito por Jones et al., ${ }^{13}$ sendo as temperaturas de incubação modificadas, $30^{\circ} \mathrm{C}$ ou $37^{\circ} \mathrm{C}$ de acordo com a temperatura de isolamento de cada bactéria, sendo observada em intervalos de $24 \mathrm{~h}$ durante três dias. A atividade proteolítica foi indicada como uma zona clara ao redor das colônias.

Para a determinação da atividade proteolítica extracelular quantitativa, as bactérias foram reativadas, depois inoculadas por mais $48 \mathrm{~h}$ em meio MS-2. De acordo com Porto etal. ${ }^{14}$ consiste em $0,1 \%(\mathrm{p} / \mathrm{v}) \mathrm{NH}_{4} \mathrm{Cl}, 0,06 \%(\mathrm{p} / \mathrm{v}) \mathrm{MgSO}_{4} \cdot 7 \mathrm{H}_{2} \mathrm{O}$, $0,453 \%(\mathrm{p} / \mathrm{v}) \mathrm{K}_{2} \mathrm{HPO}_{4}$, e $0,1 \mathrm{~mL}$ de solução mineral $(1 \mathrm{mg} / \mathrm{mL}$ $\mathrm{FeSO}_{4} \cdot 7 \mathrm{H}_{2} \mathrm{O}, 1 \mathrm{mg} / \mathrm{mL} \mathrm{MnCl}_{2} 4 \mathrm{H}_{2} \mathrm{O}, 1 \mathrm{mg} / \mathrm{mLZnSO}_{4} \mathrm{H}_{2} \mathrm{O}$ e 1 $\mathrm{mg} / \mathrm{mL} \mathrm{CaCl}$ ), a concentração final de soja foi de $2 \%$, a modificação deste meio foi a troca da glicose pela adição de $1 \%$ de lactose. A seguir, as suspensões bacterianas foram padronizadas de acordo com a escala MacFarland para $10^{7}$ células/mL, sendo inoculadas em $20 \mathrm{~mL}$ do meio MS-2 e a fermentação conduzida em Erlenmyers $(125 \mathrm{~mL})$. Aincubação foi realizada na mesma temperatura de isolamento de cada bactéria $\left(30 \pm 2^{\circ} \mathrm{C}\right.$ ou $37 \pm 2^{\circ} \mathrm{C}$ ), sob agitação a $150 \mathrm{rpm}$ por 48 horas, em agitador orbital. Decorrido o tempo de incubação, a cultura foi centrifugada para obtenção do sobrenadante livre de célula para determinação quantitativa da atividade proteásica extracelular.

A determinação da atividade proteásica foi realizada segundo o método de Alencar et al., ${ }^{15}$ em quel uma unidade de atividade enzimática foi definida como a mudança de 0,01 de absorbância a $420 \mathrm{~nm}$ por minuto.

\section{E) Atividade antagonista das bactérias ácido láticas isoladas do queijo de Coalho}

A atividade antagonista foi realizada de acordo com Guedes Neto et al., ${ }^{8}$ com a utilização de caldo MRS, para o gênero Lactobacillus e caldo APT para os demais cultivos de bactérias ácido láticas e incubação em suas temperaturas ótimas (37으 para Enterococos ou 30ㄷ para Lactococos), durante 24 horas. As cepas de patógenos de referência utilizadas como controle forma: Staphylococcus aureus ATCC6538, Escherichia coli ATCC25922 e Klebsiella pneumoniae ATCC29665, crescidas em caldo BHI (brain-heart-infusion) a $37^{\circ} \mathrm{C}$, durante 24 horas, sob aerobiose. Após o crescimento das BAL, $5 \mu \mathrm{L}$ de cada cultivo, foram colocadas sobre um disco de papel disposto na superfície de uma placa de Petri, contendo Ágar MRS ou Ágar APT, em duplicata e incubadas sob aerobiose em suas temperaturas ótimas, durante 48 horas. Após esse período, as placas foram retiradas da estufa, colocando-se nas suas tampas $1 \mathrm{~mL}$ de clorofórmio, deixandoo agir por 30 minutos em temperatura ambiente. A seguir, foram colocados 3,5mL de Agar semissólido contendo as bactérias controle. As placas contendo as cepas controle foram incubadas a $37^{\circ} \mathrm{C}$, durante 24 horas, sob aerobiose. A presença de um halo de inibição, independente do diâmetro, é indicativa do antagonismo. ${ }^{8}$

Todas as análises foram realizadas em triplicata e os resultados correspondem à média dos seus respectivos valores.

\section{RESULTADOS E DISCUSSÃO}

A identificação bioquímica revelou a diversidade de bactérias ácido láticas presentes nos queijos artesanais, com predominância de cocos, sendo o gênero com maior número de BAL encontrado neste estudo o gênero Enterococcus $(61,90 \%)$, seguido por Leuconostoc $(16,60 \%)$, Streptococcus $(9,52)$, Lactobacillus $(7,14 \%)$ e os Lactococcus que representaram $4,72 \%$ das BAL isoladas.

Cocos também foram maioria nas pesquisas de Carvalho et al. ${ }^{16}$ e Cavalcante et al. ${ }^{17}$, A diversidade de espécies é relativa e depende, primeiramente, da natureza do material isolado e dos diferentes critérios usados em cada estudo.

$O$ gênero Enterococcus foi predominante dentre as bactérias ácido láticas isoladas, o que ocorreu também nos estudos com queijo de Coalho produzido na Paraíba ${ }^{18}$ e no Ceará. ${ }^{16}$ Esse gênero tem sido frequentemente mencionado como integrante da microbiota láctea de queijos no Brasil. ${ }^{17}$

Enterococcussp são conhecidos em queijos pela produção de compostos voláteis (diacetil, acetaldeído e acetoína) e pela produção de enterocinas, que são fragmentos peptídicos capazes de inibir o crescimento de patógenos microbianos. ${ }^{19} \mathrm{~A}$ alta adaptabilidade e resistência desse gênero podem ser a justificativa para o seu desenvolvimento em vários tipos de derivados lácteos ${ }^{20} \mathrm{e}$ por prevalecerem principalmente em queijos artesanais. ${ }^{8,21}$ 
Leuconostoc sp. também foram isolados por Freitas, ${ }^{18}$ em seu estudo sobre a microbiota láctea de leite cru, queijo de Coalho e soro de leite produzidos na Paraíba. Este gênero na produção de derivados lácteos é utilizado como coadjuvante na produção de aromas. $^{22}$

O gênero Streptococcus apresentou a terceira maior proporção dentre as BAL dos queijos de Coalho artesanais produzido em Pernambuco. A presença desses microrganismos também foi observada em queijos de Coalho produzidos em outros estados do nordeste brasileiro. ${ }^{16,17}$

Os Lactobacillus se mostraram em pequena proporção (7,14\%), isso provavelmente foi em decorrência da forma de isolamento realizada, sem a utilização de anaerobiose. Os nossos resultados foram diferentes do trabalho de Resende et al. ${ }^{19}$, quando estudou o queijo de minas artesanal da Serra da Canastra, pois eles observaram que $o$ gênero foi o mais frequentemente isolado.

O gênero Lactococcus apresentou-se com o menor percentual, esse gênero é conhecido pela produção de ácidos orgânicos, além do ácido lático e pela sua atividade proteolítica, que contribue para a produção de queijos, pois colabora com o flavor característico do produto. ${ }^{19}$ Nossos resultados não corroboraram com os apresentados por Guedes Neto et al., ${ }^{8}$ que detectou grande incidência do gênero em queijos artesanais, nem com os apresentados por Ayad et al., ${ }^{12}$ cujo gênero foi predominante entre as BAL selvagens isoladas de produtos lácteos tradicionais do Egito.

Os resultados obtidos para caracterizar os isolados selecionados em relação ao seu comportamento no leite são mostrados na Tabela 1.

Os valores máximos de ácido para todos os isolados foram observados a 24h de análise, tendo os Lactobacillus alcançado os maiores valores entre $0,49 \%$ e 1,08\% de ácido lático em $3 \mathrm{~h}$ e $24 \mathrm{~h}$, respectivamente. Os menores valores de acidez em 24h deanálise foram do gênero Streptococcus, com 0,55\% de ácido lático, seguido pelo gênero Lactococcuscom $0,67 \%$ de ácido lático, sendo assim, considerados como lentos produtores de ácido.

Tratando-se do gênero Streptococcus apresentou rápida capacidade de acidificação, apenas durante as primeiras 3 h de análise, com valor médio de $0,48 \%$ de ácido lático, em 3 h de acidificação. Esses resultados foram similares aos obtidos por Badis et al. ${ }^{23}$ quanto à capacidade de acidificação observada pelo gênero Streptococcus. Estes autores em seu estudo sobre a identificação e propriedades tecnológicas de BAL isoladas de leite de cabra cru, de quatro raças da Algeria, consideraram a maioria das BAL do gênero Streptococcus como rápida produtora de ácido, mas diferiram dos nossos resultados quanto aos Lactococcus, que segundo os autores, também foram considerados como rápidos produtores de ácido, chegando a produzir mais de 0,6\% de ácido lático em $18 \mathrm{~h}$ de análise.

Em relação às bactérias ácido láticas do gênero Leuconostoc, obtiveram valores médios de 0,35\% e 0,75\% de ácido lático entre $3 \mathrm{~h}$ a $24 \mathrm{~h}$, semelhante aos resultados relatados por Badis et al., ${ }^{23} \mathrm{em}$ que amostras de Leuconostoc sp. apresentaram uma lenta produção de ácido lático. Esse gênero éheterofermentativo e sensível a baixo $\mathrm{pH}$, a condição ácida afeta o metabolismo deste tipo de micro-organismo, o Leuconostoc lactis é uma exceção, pois é capaz de acidificar o leite.

A velocidade de acidificação e a intensidade de produção de ácidos são dois aspectos importantes que devem ser considerados para a fermentação de produtos lácteos, isso porque, segundo Penna et al. ${ }^{24}$, atividade acidificante de cada cepa está relacionada com a sua capacidade específica para quebrar as substâncias no meio e torná-las capazes de assimilação.

Todas as bactérias ácido láticas isoladas dos queijos produzidos nos três municípios analisados podem ser consideradas como rápidas acidificantes de acordo com Ayad et al. ${ }^{12}$, pois foram capazes de reduzir o valor do $\mathrm{pH}$ em 0,4U até $3 \mathrm{~h}$, em relação ao valor inicial do $\mathrm{pH}$ do leite.

Essa característica de reduzir o $\mathrm{pH}$ no início da fermentação é importante para a fabricação de queijos, já que é essencial para a coagulação e redução de microrganismos contaminantes ${ }^{12}$. Além disso, a acidificação do produto a um pH próximo a 4 permite uma maior conservação do produto fermentado e auxilia na desoragem da coalhada e, mais, contribuem no desenvolvimento das propriedades sensoriais dos alimentos fermentados.

Segundo Hansen, ${ }^{25}$ essas bactérias ácido láticas podem ser utilizadas para a fabricação de queijo Muçarela, que necessita dessa rápida obtenção do $\mathrm{pH}$ ideal para filagem $(4,9-5,2)$, visando a diminuir o máximo a sinérese, durante a fermentação, e garantir a consistência adequada do produto.

Podemos observar ainda na Tabela 1 que em média as bactérias mais lentas na acidificação do leite foram as do gênero Leuconostoc. Esses resultados corroboram com os apresentados por Garabal et al. ${ }^{26}$, em que as da espécie Leuconoctoc sp. foram classificadas como lentas acidificantes, apesar de os valores finais terem sido maiores que os do presente estudo com pH 5,55 em 24h.

Essas bactérias podem ser utilizadas como parte de culturas secundárias, uma vez que uma atividade acidificante excessiva causa acidificação rápida do coágulo e alteração do teor de umidade do queijo, por isso o ideal éa combinação de cepas lentas e rápidas acidificantes. ${ }^{12}$ 
Tabela 1. Características de pH, acidez titulável, atividade proteásica e atividade antagonista das bactérias ácido láticas isoladas de queijos de Coalho artesanais produzidos na região Agreste de Pernambuco, Brasil.

Table 1. Characteristics of pH, titratable acidity, protease activity and antagonist activity of lactic acid bacteria isolated from artisanal Coalho cheese made on Agreste Region of Pernambuco State-Brazil.

\begin{tabular}{|c|c|c|c|c|c|c|c|c|c|c|c|c|c|}
\hline \multirow[t]{2}{*}{ Amostras } & \multirow{2}{*}{$\begin{array}{c}\mathrm{T} \\
\left({ }^{\circ} \mathrm{C}\right)\end{array}$} & \multicolumn{3}{|c|}{$\mathrm{pH}$} & \multicolumn{3}{|c|}{$\begin{array}{l}\text { Acidez Titulável } \\
\text { (\% de ácido lático) }\end{array}$} & \multicolumn{3}{|c|}{$\begin{array}{c}\text { Atividade proteásica } \\
(\mathrm{U} / \mathrm{mL})\end{array}$} & \multicolumn{3}{|c|}{$\begin{array}{c}\text { Atividade } \\
\text { antagonista }\end{array}$} \\
\hline & & $0 \mathrm{~h}$ & $3 \mathrm{~h}$ & $24 \mathrm{~h}$ & $0 \mathrm{~h}$ & $3 \mathrm{~h}$ & $24 \mathrm{~h}$ & $\mathrm{Oh}$ & $24 \mathrm{~h}$ & $48 \mathrm{~h}$ & $1 *$ & $2 *$ & $3 *$ \\
\hline \multicolumn{14}{|c|}{ Enterococcus $(61,90 \%)$} \\
\hline $29 \mathrm{~V}$ & 37 & 6,39 & 5,18 & 4,33 & 0,19 & 0,35 & 1,69 & 0,12 & 1,37 & 0,18 & + & + & + \\
\hline $67 \mathrm{~V}$ & 37 & 6,42 & 5,31 & 4,62 & 0,18 & 0,31 & 1,61 & 0,14 & 1,18 & 0,16 & - & - & + \\
\hline $40 \mathrm{~V}$ & 37 & 6,66 & 4,98 & 3,87 & 0,17 & 0,4 & 0,71 & 0,16 & 1,25 & 7,84 & + & + & + \\
\hline $42 \mathrm{~V}$ & 37 & 6,66 & 5,88 & 4,12 & 0,16 & 0,29 & 0,63 & 0,06 & 1,18 & 0,33 & + & - & + \\
\hline $43 \mathrm{~V}$ & 37 & 6,66 & 6,01 & 4,35 & 0,16 & 0,2 & 0,52 & 0,06 & 1,77 & 3,05 & + & - & + \\
\hline $82 \mathrm{~V}$ & 30 & 6,66 & 6,34 & 4,6 & 0,16 & 0,24 & 0,55 & 0,04 & 1,19 & 0,27 & + & + & + \\
\hline $35 \mathrm{~V}$ & 37 & 6,25 & 4,76 & 4,57 & 0,2 & 0,46 & 0,72 & 0,11 & 1,11 & 0,23 & + & + & + \\
\hline $20 \mathrm{~A}$ & 30 & 6,68 & 5,6 & 4,49 & 0,16 & 0,37 & 0,47 & 0,08 & 1,17 & 0,22 & + & - & - \\
\hline $32 \mathrm{~A}$ & 30 & 6,66 & 5,06 & 4,48 & 0,16 & 0,78 & 0,5 & 0,63 & 0,07 & 0,24 & + & + & + \\
\hline $66 \mathrm{~A}$ & 30 & 6,43 & 5,46 & 4,6 & 0,16 & 0,33 & 0,48 & 0,43 & 0,03 & 0,26 & + & + & + \\
\hline $62 \mathrm{~A}$ & 30 & 6,53 & 5,5 & 4,55 & 0,17 & 0,28 & 0,48 & 0,86 & 0,09 & 0,75 & + & + & + \\
\hline $68 \mathrm{~A}$ & 30 & 6,55 & 5,96 & 4,95 & 0,17 & 0,27 & 0,46 & 0,50 & 0,23 & 0,23 & - & - & + \\
\hline $27 \mathrm{~A}$ & 37 & 6,77 & 6,64 & 5,28 & 0,16 & 0,2 & 0,51 & 0,12 & 1,14 & 0,28 & - & - & - \\
\hline $61 \mathrm{~A}$ & 30 & 6,42 & 4,81 & 4,29 & 0,17 & 0,4 & 0,72 & 0,41 & 0,03 & 0,22 & - & - & + \\
\hline $67 \mathrm{~A}$ & 30 & 6,49 & 4,8 & 4,24 & 0,17 & 0,42 & 0,71 & 0,42 & 0,10 & 0,22 & - & + & + \\
\hline $56 \mathrm{~A}$ & 30 & 6,4 & 4,64 & 4,25 & 0,2 & 0,5 & 0,77 & 0,27 & 0,10 & 0,27 & + & - & + \\
\hline $2 \mathrm{C}$ & 37 & 6,39 & 5,57 & 4,97 & 0,2 & 0,34 & 0,46 & 0,08 & 1,12 & 0,12 & + & + & + \\
\hline $5 \mathrm{C}$ & 37 & 6,31 & 5,61 & 4,79 & 0,19 & 0,3 & 0,52 & 0,13 & 1,18 & 0,23 & + & - & - \\
\hline $6 \mathrm{C}$ & 37 & 6,43 & 5,75 & 4,68 & 0,19 & 0,29 & 0,52 & 0,15 & 1,24 & 0,28 & - & - & - \\
\hline $7 \mathrm{C}$ & 37 & 6,42 & 5,97 & 4,06 & 0,18 & 0,29 & 0,82 & 0,15 & 1,11 & 0,12 & + & - & + \\
\hline $8 \mathrm{C}$ & 37 & 6,29 & 5,5 & 4,91 & 0,22 & 0,36 & 0,46 & 0,15 & 1,16 & 0,18 & + & + & + \\
\hline $10 \mathrm{C}$ & 37 & 6,41 & 5,9 & 3,77 & 0,19 & 0,3 & 1,03 & 0,15 & 1,07 & 0,11 & + & + & - \\
\hline $11 \mathrm{C}$ & 30 & 6,36 & 5,7 & 4,71 & 0,19 & 0,33 & 0,55 & 0,18 & 1,17 & 0,17 & + & + & + \\
\hline $14 \mathrm{C}$ & 30 & 6,22 & 5,22 & 4,51 & 0,23 & 0,4 & 0,59 & 0,63 & 0,07 & 0,24 & - & - & - \\
\hline $15 \mathrm{C}$ & 30 & 6,42 & 6,13 & 3,84 & 0,22 & 0,23 & 0,57 & 0,53 & 0,10 & 0,27 & - & - & + \\
\hline \multicolumn{2}{|c|}{ Média } & $\begin{array}{c}6,48 \pm \\
0,15 \\
\end{array}$ & $\begin{array}{c}5,53 \pm \\
0,52 \\
\end{array}$ & $\begin{array}{c}4,47 \pm \\
0,37 \\
\end{array}$ & $\begin{array}{c}0,18 \pm \\
0,02 \\
\end{array}$ & $\begin{array}{c}0,35 \pm \\
0,12\end{array}$ & $\begin{array}{c}0,68 \pm \\
0,32 \\
\end{array}$ & $\begin{array}{c}0,26 \pm \\
0,22 \\
\end{array}$ & $\begin{array}{c}0,81 \pm \\
0,56\end{array}$ & $\begin{array}{c}0,66 \pm \\
1,60\end{array}$ & & & \\
\hline \multicolumn{14}{|c|}{ Leuconostoc $(16,60 \%)$} \\
\hline $68 \mathrm{~V}$ & 37 & 6,41 & 5,3 & 4,64 & 0,17 & 0,3 & 1,65 & 0,13 & 1,10 & 0,20 & + & - & - \\
\hline $19 \mathrm{~V}$ & 30 & 6,48 & 5,55 & 5,01 & 0,16 & 0,28 & 0,55 & 0,36 & 0,05 & 0,31 & + & - & - \\
\hline $47 \mathrm{~V}$ & 37 & 6,39 & 5,3 & 5,02 & 0,18 & 0,37 & 0,55 & 0,15 & 1,31 & 0,24 & - & - & - \\
\hline $23 \mathrm{~A}$ & 37 & 6,74 & 6,24 & 5,04 & 0,17 & 0,27 & 0,56 & 0,13 & 1,20 & 0,16 & + & + & + \\
\hline $49 \mathrm{~A}$ & 30 & 6,43 & 5,4 & 4,45 & 0,19 & 0,45 & 0,86 & 0,64 & 0,10 & 0,26 & + & + & + \\
\hline $9 \mathrm{C}$ & 37 & 6,15 & 5,33 & 4,76 & 0,22 & 0,36 & 0,52 & 0,12 & 1,13 & 0,19 & + & - & - \\
\hline $12 \mathrm{C}$ & 30 & 5,9 & 5,24 & 4,59 & 0,23 & 0,4 & 0,57 & 0,64 & 0,05 & 0,24 & + & + & + \\
\hline \multicolumn{2}{|c|}{ Média } & $\begin{array}{c}6,36 \pm \\
0,27 \\
\end{array}$ & $\begin{array}{c}5,48 \pm \\
0,35\end{array}$ & $\begin{array}{c}4,79 \pm \\
0,24 \\
\end{array}$ & $\begin{array}{c}0,19 \pm \\
0,03 \\
\end{array}$ & $\begin{array}{c}0,35 \pm \\
0,07\end{array}$ & $\begin{array}{r}0,75 \pm \\
0,41\end{array}$ & $\begin{array}{c}0,31 \pm \\
0,24\end{array}$ & $\begin{array}{c}0,71 \pm \\
0,60\end{array}$ & $\begin{array}{c}0,23 \pm \\
0,04\end{array}$ & & & \\
\hline
\end{tabular}

Continua / To be continued 


\begin{tabular}{|c|c|c|c|c|c|c|c|c|c|c|c|c|c|}
\hline \multirow[t]{2}{*}{ Amostras } & \multirow{2}{*}{$\begin{array}{c}\mathrm{T} \\
\left({ }^{\circ} \mathrm{C}\right)\end{array}$} & \multicolumn{3}{|c|}{$\mathrm{pH}$} & \multicolumn{3}{|c|}{$\begin{array}{l}\text { Acidez Titulável } \\
\text { (\% de ácido lático) }\end{array}$} & \multicolumn{3}{|c|}{$\begin{array}{c}\text { Atividade proteásica } \\
(\mathrm{U} / \mathrm{mL})\end{array}$} & \multicolumn{3}{|c|}{$\begin{array}{c}\text { Atividade } \\
\text { antagonista }\end{array}$} \\
\hline & & $0 \mathrm{~h}$ & $3 \mathrm{~h}$ & $24 \mathrm{~h}$ & $0 \mathrm{~h}$ & $3 \mathrm{~h}$ & $24 \mathrm{~h}$ & Oh & $24 \mathrm{~h}$ & $48 \mathrm{~h}$ & $1 *$ & $2^{*}$ & $3 *$ \\
\hline \multicolumn{14}{|c|}{ Streptococcus $(9,52 \%)$} \\
\hline $110 \mathrm{~V}$ & 30 & 6,47 & 5,42 & 4,42 & 0,17 & 0,35 & 0,71 & 0,52 & 0,49 & 0,23 & + & + & + \\
\hline $24 \mathrm{~A}$ & 30 & 6,68 & 5,54 & 4,81 & 0,16 & 0,52 & 0,48 & 0,08 & 1,08 & 0,18 & + & + & + \\
\hline $29 \mathrm{~A}$ & 30 & 6,54 & 4,98 & 4,41 & 0,15 & 0,67 & 0,49 & 0,53 & 0,08 & 0,20 & + & - & + \\
\hline $51 \mathrm{~A}$ & 30 & 6,42 & 5,32 & 4,43 & 0,4 & 0,44 & 0,49 & 0,63 & 0,20 & 0,24 & + & - & - \\
\hline $13 \mathrm{C}$ & 30 & 6,22 & 5,27 & 4,46 & 0,23 & 0,4 & 0,59 & 0,46 & 0,09 & 0,18 & - & + & + \\
\hline \multicolumn{2}{|c|}{ Média } & $\begin{array}{c}6,47 \pm \\
0,17\end{array}$ & $\begin{array}{c}5,31 \pm \\
0,21\end{array}$ & $\begin{array}{c}4,51 \pm \\
0,17\end{array}$ & $\begin{array}{c}0,22 \pm \\
0,10\end{array}$ & $\begin{array}{c}0,48 \pm \\
0,13\end{array}$ & $\begin{array}{c}0,55 \\
\pm 0,10\end{array}$ & $\begin{array}{c}0,44 \pm \\
0,20\end{array}$ & $\begin{array}{c}0,39 \pm \\
0,42\end{array}$ & $\begin{array}{c}0,21 \pm \\
0,02\end{array}$ & & & \\
\hline \multicolumn{14}{|c|}{ Lactobacillus $(7,14 \%)$} \\
\hline $56 \mathrm{~V}$ & 37 & 6,35 & 5,06 & 4,34 & 0,18 & 0,32 & 1,7 & 0,13 & 1,10 & 0,20 & - & - & + \\
\hline $41 \mathrm{~V}$ & 37 & 6,55 & 5,06 & 3,89 & 0,18 & 0,42 & 0,68 & 0,27 & 1,38 & 11,72 & + & - & - \\
\hline $96 \mathrm{~V}$ & 30 & 6,61 & 5,89 & 3,94 & 0,2 & 0,72 & 0,85 & 0,46 & 0,13 & 0,21 & - & + & + \\
\hline \multicolumn{2}{|c|}{ Média } & $\begin{array}{c}6,45 \pm \\
0,14\end{array}$ & $\begin{array}{c}5,34 \pm \\
0,48\end{array}$ & $\begin{array}{c}4,06 \pm \\
0,25\end{array}$ & $\begin{array}{c}0,19 \pm \\
0,01\end{array}$ & $\begin{array}{c}0,49 \pm \\
0,21\end{array}$ & $\begin{array}{r}1,08 \pm \\
0,55\end{array}$ & $\begin{array}{c}0,29 \pm \\
0,16\end{array}$ & $\begin{array}{c}0,87 \pm \\
0,65\end{array}$ & $\begin{array}{c}4,04 \pm \\
6,64\end{array}$ & & & \\
\hline \multicolumn{14}{|c|}{ Lactococcus $(4,72 \%)$} \\
\hline $57 \mathrm{~A}$ & 30 & 6,42 & 5,1 & 4,41 & 0,17 & 0,37 & 0,53 & 0,40 & 0,03 & 0,31 & + & + & + \\
\hline 69A & 30 & 6,42 & 4,82 & 4,28 & 0,2 & 0,48 & 0,81 & 0,56 & 0,23 & 0,18 & - & + & + \\
\hline Médi & & $\begin{array}{c}6,42 \pm \\
0,00\end{array}$ & $\begin{array}{c}4,96 \pm \\
0,20\end{array}$ & $\begin{array}{c}4,35 \pm \\
0,09\end{array}$ & $\begin{array}{c}0,19 \pm \\
0,02\end{array}$ & $\begin{array}{c}0,43 \pm \\
0,08\end{array}$ & $\begin{array}{c}0,67 \pm \\
0,20\end{array}$ & $\begin{array}{c}0,48 \pm \\
0,11\end{array}$ & $\begin{array}{c}0,13 \pm \\
0,13\end{array}$ & $\begin{array}{c}0,24 \pm \\
0,09\end{array}$ & & & \\
\hline
\end{tabular}

*1= Escherichia coli, 2= Klebsiella pneumoniae e 3=Staphylococus aureus; $+=$ presença de antagonismo, - = ausência de antagonismo.

$* 1=$ Escherichia coli, $2=$ Klebsiella pneumoniae e 3= Staphylococus aureus $;+=$ presence of antagonism, $-=$ absence of antagonismo.

As bactérias selvagens estudadas neste trabalho apresentam potencial tecnológico promissor para produção de derivados do leite em indústrias, como as de culturas starters.

Duas bactérias pertencentes aos gêneros Lactobacillus e Enterococcus exibiram atividade proteolítica, ou seja, presença de halo; entretanto as demais cresceram, significando que apresentam enzimas proteolíticas, mas não apresentaram halo. Esses resultados foram similares aos de Silva, ${ }^{27}$ que trabalhou com microbiota lática isolada de queijo Muçarela de búfala e observou que uma cultura mesófila de Lactobacillus também teve atividade proteolítica.

Os resultados obtidos para a produção de proteases extracelulares se encontram na Tabela 1. Dentre as $42 \mathrm{BAL}$ estudadas, duas cepas apresentaram altos valores de atividade enzimática 7,84U/mL, correspondendo a uma cepa de Enterococcuse de 11,71 U/mL, correspondendo a uma cepa Lactobacillus. Estas se destacaram entre as demais por obter os maiores picos de produção em $48 \mathrm{~h}$. E, assim, a atividade proteolítica com o maior valor de produção foi relacionada ao gênero Lactobacillus.
Os resultados referentes à atividade antagonista estão apresentados na Tabela 1, entre estes podem ser observados que entre as 42 BAL testadas, $90 \%$ exibiram atividade antagonista frente a pelo menos uma cepa indicadora, apenas quatro cepas (10\%) dos gêneros Enterococcus e Leuconostoc não conseguiram apresentar antagonismo em relação a nenhum dos micro-organismos testados (Escherichia coli, Klebsiella pneumoniae e Staphylococcus aureus); Entre as bactérias que exibiram atividade antagonista, $42,2 \%$ inibiram as três bactérias indicadoras testadas; $28,9 \%$ inibiram pelo menos uma bactéria indicadora, e as demais (28,9\%) apresentaram atividade inibitória contra duas das bactérias indicadoras.

As cepas de Enterococcus sp. apresentaram maior antagonismo frente as três bactérias de referência, seguidas dos Leuconostocsp, Streptococcus sp. e Lactococcus sp. Entretanto, os maiores halos de inibição (16, 20 e 17 mm) foram produzidos por três Streptococcus contra a Klebsiella pneumoniae eStaphylococcus aureus (dados não mostrados).

Esses resultados diferiram dos encontrados por Alexandre et al., ${ }^{28}$ que trabalharam com atividade antimicrobiana de bactérias ácido láticas isoladas de queijo- 
de-minas artesanal do Serro (MG), frente a micro-organismos indicadores e observaram que a Escherichia coli não foi inibida por nenhum sobrenadante das bactériasácido láticas testadas pelos autores.

Bromberg et al..$^{29}$ analisaram a capacidade inibitória de uma bacteriocina produzida por Lactococcus lactis ssp. hordniae CTC 484 e esta, por sua vez, inibiu o crescimento de Staphylococcus aureus CTC 033, mas não foi capaz de inibir o crescimento de Escherichia colinas em mesmas condições de cultivo, mostrando, assim, que essa bacteriocina não foi efetiva contra bactérias Gram-negativas. Estes resultados concordam com os nossos, 42,2\%das BAL que apresentaram atividades antagonistas não conseguiram inibir ao mesmo tempo cepas Gram positivas e Gram negativas, e isto pode ser devido à natureza da bacteriocina produzida.

No trabalho de Alexandre et al. ${ }^{28}$, aproximadamente $15 \%$ das bactérias ácido láticas isoladas conseguiram inibir cepas de Staphylococcus aureus, esses valores foram inferiores aos nossos resultados, nos quais aproximadamente $71,4 \%$ das BAL apresentaram antagonismo contra essa espécie.

Dentre as cepas de Lactobacillus isoladas, apenas uma conseguiu inibir Escherichia coli. Esses resultados diferiram dos apresentados por Chioda et al., ${ }^{29}$ quando analisaram a capacidade de Lactobacillus acidophilus em inibir o crescimento de Escherichia coli isolada de Queijo "Minas Frescal" e verificaram que todas as cepas de Lactobacillus mostraram-se capazes de inibir a bactéria alvo.

Vários trabalhos descrevem atividade antagonista de bactérias ácido láticas frente a outras bactérias Grampositivas, ${ }^{8,28,29}$ entretanto contra as bactérias Gram-negativas, o antagonismo não é frequente, mas já houve relatos desse tipo de inibição. 30,31

As atividades antagonistas, juntamente à capacidade de acidificação e produção de proteases, representam fatores importantes na tecnologia de alimentos. É justamente por produzirem e tolerarem uma grande concentração de ácido lático que elas conseguem inibir outros micro-organismos nos alimentos, incluindo os patogênicos.

Tendo em vista a importância socioeconômica e de saúde pública da fabricação de novos fermentos biológicos constituídos por novas cepas bactérias ácido láticas, as quais estão sendo bastante estudadas para uma melhor utilização nesses e em outros alimentos. Além disso, a utilização delas como bioconservadores mostra-se como alternativa na conservação de produtos alimentícios. ${ }^{6}$

\section{CONCLUSÕES}

As 42 bactérias ácido láticas isoladas de queijos de Coalho artesanais produzidos nos municípios avaliados foram promissoras em relação a aspectos tecnológicos importantes para a indústria de laticínios, por serem capazes de sobreviver à acidificação láctea, de produzir proteases e substâncias como bacteriocinas, já que foi observada a inibição do crescimento de patógenos em $90 \%$ das BAL neste trabalho. Sendo esse fato relevante para a segurança microbiológica do alimento a ser produzido com estes micro-organismos. Pode-se, então, concluir que estas cepas possuem características importantes para a indústria de produtos lácteos na utilização como culturas starters.

\section{CONTRIBUIÇÃO AUTORES}

Os autores Maria Luiza Barros Cabral, Meire dos Santos Falcão de Lima, Gabriela Alves de Araújo Fernandes e Eduardo Felipe da Costa participaram na condução do experimento.

As autoras Ana Lúcia Figueiredo Porto e Maria Taciana Holanda Cavalcanti do planejamento, orientação e da revisão final do artigo.

\section{CONFLITO DE INTERESSE}

Os autores declaram que não há conflito de interesse.

\section{FINANCIAMENTO}

Os autores reportam que houve suporte e auxilio financeiro durante o desenvolvimento da pesquisa pelo CNPQ processo (557665/2009-4).

\section{COMO CITAR O ARTIGO}

\section{ABNT}

CABRAL, Maria Luiza Barros et al. Queijos artesanais fonte de bactérias ácido láticas selvagens para formulação de fermentos tradicionais. Joumal of bioenergy and food science, v.3, n.4, p.207-215, 2016. DOl:10.18067/jbfs.v3i4.112.

\section{APA}

Cabral, M., Lima, M., Fernandes, G., Costa, E., Porto, A., \& Cavalcanti, M. (2016). Queijos artesanais: fonte de bactérias ácido láticas selvagens para formulação de fermentos tradicionais Journal of Bioenergy and Food Science, 3(4), p.207-215. DOl:10.18067/jbfs.v3i4.112

\section{REFERÊNCIAS}

(1).QUEIROGA, R. C. R. E.; SANTOS, B. M.; GOMES, A. M. P.; MONTEIRO, M. J.; TEIXEIRA, S. M.; SOUZA, E. L.; PEREIRA, C. J. D.; PINTADO, M. M. E. Nutritional, textural and sensory properties of Coalho cheese made of goats', cows' milk and their mixture. LWT Food Science and Technology, v.50, n.2, p.538-544, 2013. DOI:10.1016/j.lwt.2012.08.011

(2).SILVA, R. A.; LIMA, M. S. F.; VIANA, J. B. M.; BEZERRA, V. S.; PIMENTEL, M. C. B.; PORTO, A. L. F.; CAVALCANTI, M. T. H.; LIMA 
FILHO, J. L. Can artisanal "Coalho" cheese from Northeastern Brazil be used as a functional food? Food Chemistry, v. 35, n.1, p.15331538, 2012. DOI:10.1016/j.foodchem.2012.06.058

(3).FRANCIOSI, E.; SETTANNI, L.; CAVAZZA, A.; POZNANSKI, E. Biodiversity and technological potential of wild lactic acid bacteria from raw cows' milk. International. Dairy Journal, v.19, n.1, p.3-11, 2009. DOI:10.1016/j.idairyj.2008.07.008

(4).DOLCl, P.; ALESSANDRIA, V.; ZEPPA, G.; RANTSIOU, K.; COCOLIN, L. Microbiological characterization of artisanal Raschera PDO cheese: Analysis of its indigenous lactic acid bacteria. Food Microbiology, v.25, n.2,p.392-399,2008. DOI:10.1016/j.fm.2007.09.006

(5).SILVA, R.A.; BISMARA, P.A.; MOURA, R.B.; LIMA FILHO, J.L.; PORTO, A.L.F.; CAVALCANTI, M.T.H. Avaliação da microbiota bacteriana do queijo de coalho artesanal produzido na região Agreste do estado de Pernambuco. Arquivo Brasileiro de Medicina Veterinária e Zootecnia, v.64, n.2, p.1732-1738, 2012. DOI:10.1590/S0102-09352012000600044

(6).VIEGAS, R. P.; SOUZA, M. R.; FIGUEIREDO, T. C.; RESENDE, M. F. S.; PENNA, C. F. A. M.; CERQUEIRA, M. M. O. P. Qualidade de leites fermentados funcionais elaborados a partir de bactérias ácidolácticas isoladas de queijo de coalho. Arquivo Brasileiro de Medicina Veterinária e Zootecnia, v.62, n.2, p.460-467, 2010. DOI:10.1590/S0102-09352010000200028

(7). POPPI, L. B.; MANCILHA, I. M.; FERREIRA, A. J. P.; LEAL, D. D. M. Nota prévia: Avaliação do efeito antagônico de espécies de Lactobacillus sobre Listeria monocytogenes in vitro. Brazilian Journal of Food Technology, v. 11, n.2, p.113-119, 2008.

(8). GUEDES NETO, L.G.; SOUZA, M.R.; Nunes, A.C.; Nicoli, J.R.; Santos, W.L.M. Atividade antimicrobiana de bactérias ácido-lácticas isoladas de queijos de coalho artesanal e industrial frente a microrganismos indicadores. Arquivos Brasileiro de Medicina Veterinária e Zootecnia, v.57, n.2, p.245-250, 2005. DOI:10.1590/S0102-09352005000800017

(9). LIMA, M. S.; RÉVILLION, J. P.P.; PÁDULA, A. D. Estratégias competitivas e de desenvolvimento de produtos lácteos funcionais: estudos de caso em empresas agroindustriais da região Sul do Brasil. Ciência Rural, v.39, n.5, p.1547-1551, 2009. DOI:10.1590/S010384782009005000134

(10). SOARES, D. S.; FAI, A. E. C.; OLIVEIRA, A. M.; PIRES, E. M. F.; STAMFORD, T. L. M. The use of cheese whey for probiotic yogurt production. Arquivo Brasileiro de Medicina Veterinária e Zootecnia, v.63, n.4, p.996-1002, 2011. DOI:10.1590/S010209352011000400027

(11). MEIRA, S. M. M.; HELFER, V.E.; VELHO, R. V.; MEDINA, L. F. C.; BRANDELLI, A. Identificação e resistência a barreiras biológicas de bactérias lácticas isoladas de leite e queijo de ovelha. Brazilian Journal of Food Technology, n.12, p.75-80, 2010. DOI:10.4260/BJFT20101304112

(12). AYAD, E. H. E.; NASHAT, S.; EL-SADEK, N.; METWALY, H.; ELSODA, M. Selection of wild lactic acid bacteria isolated from traditional Egyptian dairy products according to production and technological criteria. Food Microbiology, v. 21, n.6, p.715-725, 2004. DOI:10.1016/j.fm.2004.02.009

(13).JONES, B.V.; SUN, F.; MARCHESI, J.R. Using skimmed milk agar to functionally screen a gut metagenomic library for proteases may lead to false positives. Applied Microbiology, v.45, n.4, p.418-420, 2007. DOI:10.1111/j.1472-765X.2007.02202.x

(14).PORTO, A. L. F., CAMPOS-TAKAKI, G. M.; FILHO, J. L. L. Effects of culture conditions on protease production by Streptomyces clavuligerus growing on soy bean flour medium. Applied Biochemistry and Biotechnology, v.60, n.2, p.115-122, 1996. DOI:10.1007/BF02788066

(15). ALENCAR, R. B; BIONDI, M.M.; PAIVA, P.M.G.; VIEIRA, V.L.A.; JUNIOR, L.B.C. Alkaline Proteases from the Digestive Tract of Four Tropical Fishes. Brazilian Journal Food Technology, v.6, n.2, p.279284, 2003.

(16).CARVALHO, J. D. G.; BRUNO, L. M.; NASSU, R. T.; LIMA, C. P.; VASCONCELOS, N. M.; KUAYE, A. Y. Avaliação da Capacidade de Produção de Ácido por Bactérias Ácido Isoladas de Leite e de Queijos de Coalho Artesanais produzidos no Ceará. Revista do Instituto de Laticínios Cândido Tostes, v.61, n.351, p. 306-309, 2006.

(17).CAVALCANTE, J.F.M.; ANDRADE, N.J.; FURTADO, M.M.; FERREIRA, C.L.L.F.; PINTO, C.L.O.; ELARD, E. Processamento do queijo coalho regional empregando leite pasteurizado e cultura lática endógena. Ciência e Tecnologia de Alimentos. v.27, n.1, p.205-214, 2007. DOI:10.1590/S0101-20612007000100036

(18).FREITAS, W. C.; TRAVASSOS, A. E. R.; MACIEL, J. F. Avaliação microbiológica e físico-química de leite cru e queijo de coalho produzidos no estado da Paraíba. Revista Brasileira de Produtos Agroindustriais, v.15, n.1, p.35-42, 2013.

(19).RESENDE, M.F.S.; COSTA, H.H.S.; ANDRADE, E.H.P.; ACÚRCIO, L.B.; DRUMMOND, A.F.; CUNHA, A.F.; NUNES, A.C.; MOREIRA, J.L.S.; PENNA, C.F.A.M.; SOUZA, M.R. Queijo de minas artesanal da Serra da Canastra: influência da altitude das queijarias nas populações de bactérias ácido lácticas. Arquivo Brasileiro de Medicina Veterinária e Zootecnia, v.63, n.6, p.1567-1573, 2011. DOI:10.1590/S0102 09352011000600039

(20). MARTÍN-PLATERO, A. M.; VALDIVIA, E.; MAQUEDA, M.; MARTÍNEZ-BUENO, M. Characterization and safety evaluation of enterococci isolated from Spanish goats' milk cheeses. International Journal of Food Microbiology, v132, n.1, p.24-32, 2009. DOI:10.1016/j.ijfoodmicro.2009.03.010

(21). SANTOS, K.M.O.; VIEIRA, A.D.S.; ROCHA, C.R. C.; NASCIMENTO, J C.F.; LOPES, A.C.S.; BRUNO, L.M.; CARVALHO, J.D.G.; FRANCO, B.D.G.M.; TODOROV, S.D. Brazilian artisanal cheeses as a source of beneficial Enterococcus faecium strains: characterization of the bacteriocinogenic potential. Annals of Microbiology, v.1, n.4 p.1-9, 2014.DOI:10.1007/s13213-013-0789-4

(22).DE PAULA, A. T.; JERONYMO-CENEVIVA, A. B.; SILVA, L. F.; TODOROV, S. D.; FRANCO, B. D. G. M.; PENNA, A. L. B. Leuconostoc mesenteroides SJRP55: a potential probiotic strain isolated from 
Brazilian water buffalo mozzarella cheese. Annals of Microbiology, v.7, n.2, p.1-13, 2014. DOI:10.1007/s13213-014-0933-9

(23). BADIS, A.; GUETARNI, D.; MOUSSA-BOUDJEMÂA, B.; HENNIC, D.E., TORNADIJOD, M.E.; KIHAL, M. Identification of cultivable lactic acid bacteria isolated from Algerian raw goat's milk and evaluation of their technological properties. Food Microbiology, v.21, n.3, p.343-349, 2003. DOI:10.1016/S0740-0020(03)00072-8

(24). PENNA, A. L. B.; PAULA, A. T.; CASAROTTI, S. N.; DIAMANTINO, V. R.;SILVA, L. F. Overview of the functional lactic acid bacteria in the fermented milk products. Beneficial Microbes in Fermented and Functional Foods, v. 1, p. 100-154, 2015.

(25).HANSEN, C. O papel das culturas láticas na fabricação de muçarela. Food Ingredients Brasil, n 23, p. 26-27, 2012.

(26).GARABAL, J. I.; ALONSO, P.R.; CENTEN, J. A. Characterization of lactic acid bacteria isolated from raw cows' milk cheeses currently produced in Galicia (NW Spain). LWT-Food Science and Technology, v.41,n.8,p.1452-1458,2007. DOI:10.1016/j.Iwt.2007.09.004

(27).SILVA, L. F.; CASELLA, T.; GOMES, E. S.; NOGUEIRA, M. C. L.; DEA- LINDNER, J.; PENNA, A. L. B. Diversity of Lactic Acid Bacteria Isolated from Brazilian Water Buffalo Mozzarella Cheese. Journal of Food Science, v.80, n.2, p.411-417, 2015. DOl:10.1111/17503841.12771
(28).ALEXANDRE, D.P.; SILVA, M.R.; SOUZA, M.R.; SANTOS, W.L.M. Atividade antimicrobiana de bactérias lácticas isoladas de queijo-deminas artesanal do Serro (MG) frente a microrganismos indicadores. Arquivo Brasileiro de Medicina Veterinária e Zootecnia., v.54, n.4, p.424-428, 2002. DOI:10.1590/S010209352002000400014

(29).BROMBERG, R.; MORENO, I.; DELBONI, R. R.; CINTRA, H. C. Características da bacteriocina produzida por Lactococcus lactis ssp. hordniae CTC 484 e seu efeito sobre Listeria monocytogenes em carne bovina. Ciência e Tecnologia de Alimentos, v.26, n.1, p.135144, 2006. DOI:10.1590/S0101-20612006000100023

(30).CHIODA T.P; SCHOCKEN-ITURRINO R. P.; GARCIA G. R.; PIGATTO C. P.; C. A. M. RIBEIRO; RAGAZZANI A. V. F. Inibição do crescimento de Escherichia coli isolada de Queijo "Minas Frescal" por Lactobacillus acidophilus. Ciência Rural. Santa Maria, v.37, n.2, p.583-585, 2007. DOI:10.1590/S0103-84782007000200048

(31).JATOBÁ, A.; VIEIRA F. N.; NETO C. B.; SILVA B. C.; MOURIÑO, J. L. P.; JERÔNIMO G. T.; DOTTA, G.; MARTINS, M. L. Utilização de bactérias ácido-lácticas isoladas do trato intestinal de tilapia-do-nilo como probiótico. Pesquisa Agropecuária Brasileira, v.43, n.9, p.1201-1207, 2008. DOl:10.1590/\$0100-204X2008000900015 